\title{
An epigenetic hypothesis for the genomic memory of pain
}

\author{
Sebastian Alvarado 1,2,3†, Maral Tajerian 4,5,6t, Matthew Suderman ${ }^{2,3}$, Ziv Machnes ${ }^{2,3}$, \\ Stephanie Pierfelice ${ }^{2,3}$, Magali Millecamps ${ }^{6,7}$, Laura S. Stone ${ }^{2,5,6,7,8}$ and Moshe Szyf $2,3,5 *$ \\ ${ }^{1}$ Department of Biology, Stanford University, Palo Alto, CA, USA, ${ }^{2}$ Department of Pharmacology and Therapeutics, Faculty \\ of Medicine, McGill University, Montréal, QC, Canada, ${ }^{3}$ Sackler Program for Epigenetics and Developmental Psychobiology, \\ McGill University, Montréal, QC, Canada, ${ }^{4}$ Department of Anesthesiology, Stanford University, Palo Alto, CA, USA, \\ ${ }^{5}$ Integrated Program in Neuroscience, Mc Gill University, Montréal, QC, Canada, ${ }^{6}$ Alan Edwards Centre for Research on \\ Pain, McGill University, Montréal, QC, Canada, ${ }^{7}$ Faculty of Dentistry, McGill University, Montréal, QC, Canada, ${ }^{8}$ Department \\ of Anesthesiology, Anesthesia Research Unit, Faculty of Medicine, McGill University, Montréal, QC, Canada
}

OPEN ACCESS

Edited by: Marco Martina, Northwestern University, USA

Reviewed by: Stefano Gustincich, International School for Advanced Studies SISSA, Italy Franziska Denk,

King's College London, UK

*Correspondence:

Moshe Szyf, Department of Pharmacology and Therapeutics, Faculty of Medicine, McGill University, 3655 Promenade Sir William Osler, Montréal, QC H3G 1Y6, Canada moshe.szyґ@mcgill.ca

${ }^{\dagger}$ These authors have contributed equally to this work.

Received: 15 October 2014 Accepted: 26 February 2015 Published: 24 March 2015

Citation: Alvarado S, Tajerian M, Suderman M, Machnes Z, Pierfelice S, Millecamps $M$, Stone LS and Szyf M (2015) An epigenetic hypothesis for the genomic memory of pain. Front. Cell. Neurosci. 9:88. doi: 10.3389/fncel.2015.00088
Chronic pain is accompanied with long-term sensory, affective and cognitive disturbances. What are the mechanisms that mediate the long-term consequences of painful experiences and embed them in the genome? We hypothesize that alterations in DNA methylation, an enzymatic covalent modification of cytosine bases in DNA, serve as a "genomic" memory of pain in the adult cortex. DNA methylation is an epigenetic mechanism for long-term regulation of gene expression. Neuronal plasticity at the neuroanatomical, functional, morphological, physiological and molecular levels has been demonstrated throughout the neuroaxis in response to persistent pain, including in the adult prefrontal cortex (PFC). We have previously reported widespread changes in gene expression and DNA methylation in the PFC many months following peripheral nerve injury. In support of this hypothesis, we show here that up-regulation of a gene involved with synaptic function, Synaptotagmin II (syt2), in the PFC in a chronic pain model is associated with long-term changes in DNA methylation. The challenges of understanding the contributions of epigenetic mechanisms such as DNA methylation within the PFC to pain chronicity and their therapeutic implications are discussed.

Keywords: chronic pain, epigenetics, neuropathy, prefrontal cortex, DNA methylation, synaptotagmin, neuroplasticity

\section{Chronic Pain is Associated with Anatomical, Morphological, and Physiological Changes in the Adult Prefrontal Cortex}

Chronic pain is associated with a multitude of co-morbidities, including depression, anxiety, cognitive impairment, memory deficits and loss of motivation both in humans (Sharp and Keefe, 2005) and in animal models (Low, 2013; Schwartz et al., 2014; Tajerian et al., 2014). Rather than the pain itself, these higher-order functions, mediated by supra-spinal structures, can have the biggest impact on quality of life in chronic pain patients (Nicholson and Verma, 2004).

Chronic pain changes brain anatomy and function. Studies in rodent models of chronic pain have demonstrated pain-related modifications in areas including the hippocampus, amygdala, perirhinal cortex, and prefrontal cortex (PFC; Seminowicz et al., 2009; Mutso et al., 2012; Alvarado et al., 2013; Tajerian et al., 2013, 2014). These findings extend to humans-multiple studies have reported decreased gray matter, reduced cortical thickness, 
abnormal cortical function, and altered connectivity in various brain regions in a wide range of chronic pain conditions including low back pain (Giesecke et al., 2004; Apkarian et al., 2005; Schmidt-Wilcke et al., 2006; Tagliazucchi et al., 2010; Berger et al., 2014), headache (Schmidt-Wilcke et al., 2005), fibromyalgia (Kuchinad et al., 2007; Schmidt-Wilcke et al., 2007), post-stroke pain (Krause et al., 2014), complex regional pain syndrome (Pleger et al., 2014), burning mouth syndrome (Khan et al., 2014), and irritable bowel syndrome (Davis et al., 2008). The magnitude of these changes has been related to the duration and the intensity of chronic pain (Apkarian et al., 2004).

While changes in some brain regions are associated with specific chronic pain conditions, most studies report changes in common areas involved in pain modulation, including the PFC (Apkarian et al., 2009; Neugebauer et al., 2009). Interestingly, the PFC has been implicated in depression, anxiety and cognitive impairment, all of which are frequently associated with chronic pain. Painrelated pathological changes in the PFC may therefore contribute to the emergence of emotional and cognitive impairments.

In order to determine if chronic pain could induce painrelated changes in brain anatomy, Seminowicz et al. conducted a longitudinal study of chronic neuropathic pain in rats (Seminowicz et al., 2009). Consistent with the human literature, pain-related decreases in frontal cortex volume were observed in rats subjected to peripheral nerve injury as adults. These changes were not observed until approximately 4 months postinjury and were temporally correlated with the development of anxiety-like symptoms in the same animals. Thus, pain-related changes in the PFC are a consequence of chronic, but not acute pain.

At the molecular/cellular level, animal studies have demonstrated neuropathy-induced altered dendritic branching and spine density. For example, basal dendrites had longer branches in the PFC in animals with peripheral nerve injury than in controls (Metz et al., 2009). Changes in neuroanatomy are also linked to functional differences within the firing of pyramidal neurons (Centeno et al., 2009; Metz et al., 2009) and reduced connectivity between the PFC and other brain regions (Cardoso-Cruz et al., 2013a,b).

Ongoing chronic pain not only induces changes in the PFC but also actively maintains them. We have shown that pathological changes in the PFC in individuals with chronic low back pain (cLBP) can be reversed with effective pain management (Seminowicz et al., 2011). Specifically, cLBPassociated cortical thinning in the dorsolateral PFC (DLPFC) was reversed post-treatment, and the magnitude of this reversal correlated with the reduction of both pain and physical disability. Furthermore, abnormal activity in the DLPFC during an attention-demanding cognitive task in cLBP patients was reduced towards normal levels following treatment. The ability of the adult PFC to undergo neuroplastic changes is further supported by studies in healthy subjects (Hötting and Röder, 2013). For example, increased physical activity resulted in improved memory and increased local gray matter
TABLE 1 | Classification of transcriptome-identified promoters.

\begin{tabular}{lcccc}
\hline $\begin{array}{l}\text { Gene } \\
\text { type }\end{array}$ & $\begin{array}{c}\text { Number } \\
\text { of genes* }\end{array}$ & $\begin{array}{c}\text { Differentially } \\
\text { expressed* }\end{array}$ & $\begin{array}{c}\text { Enrichment } \\
\boldsymbol{p} \text {-value** }\end{array}$ & $\begin{array}{c}\text { Enrichment } \\
\text { status }^{+}\end{array}$ \\
\hline Housekeeping & 3292 & 29 & $1.60 \mathrm{E}-13$ & Depleted \\
Weak promoter & 5262 & 118 & 0.07 & Depleted \\
Narrow promoter & 930 & 43 & $1.20 \mathrm{E}-04$ & Enriched \\
Broad promoter & 1279 & 51 & $9.50 \mathrm{E}-04$ & Enriched \\
Bivalent & 3400 & 166 & $4.90 \mathrm{E}-18$ & Enriched
\end{tabular}

*Considers only protein coding genes. ${ }^{\star *}$ Enrichment was tested by Fisher's exact test. ${ }^{+}$Depleted/enriched identify cases where the number of genes is smaller/larger than expected.

volume in the PFC in adult volunteers (Ruscheweyh et al., 2011).

These data indicate that long-term structural and functional brain abnormalities-specifically in the PFC-are induced by chronic pain. Furthermore, they suggest that treating chronic pain can restore normal brain function in the adult human PFC and raise the possibility that therapies targeting pathological changes in the PFC have therapeutic utility. Finally, the reversibility suggests that these changes are unlikely to be due to neurotoxicity; in contrast, the underlying mechanisms must be both long-lasting and reversible.

\section{Pain-Related Changes in Gene Expression in the Adult Prefrontal Cortex}

Given the extensive structural and functional abnormalities in the PFC associated with pain persistent changes in genomic programming are likely to contribute to both chronic pain and to the associated co-morbidities. For example, in a model of acute facial pain, genes related to immune function and neutrophil activation are over-expressed in the PFC (Poh et al., 2012). In chronic neuropathic pain, we observed differential RNA expression of 1147 genes. Some of these genes are associated with functional pathways involved in neuronal development, cell differentiation and growth in the PFC 6 months following peripheral nerve injury (Alvarado et al., 2013). Furthermore, the majority of these differentially expressed transcripts were enriched for narrow, broad and bivalent types of promoters (Table 1, Lenhard et al., 2012). That is, narrow and weak promoters represent tissue specific and general cell cycle processes, respectively. This suggests that transcriptional landscape is accompanied with changes that are enriched for tissue-specific changes than those involved with the general cell cycle. Given the scope of long-term anatomical changes and the large number of differentially expressed transcripts, the transcriptional machinery itself is likely to become dysregulated as chronic pain progresses. Within upregulated transcriptional networks, we identified pathways that were relevant to cellular growth, differentiation, structural function and neuronal function (Alvarado et al., 2013). This is important since pain-related structural and functional changes may involve several of these pathways in degenerative/regenerative changes in the cortex due to altered neuronal/dendritic architecture (Freeman et al., 2008), glial loss 
or modifications to the extracellular environment (Tajerian and Clark, 2015).

Within the differentially expressed transcripts associated with nerve injury, one third were annotated proteincoding transcripts, and the remaining were an assortment of non-coding RNAs of various identities (lincRNAs, miRNAs, etc.). These data offers additional insight into the function of previously uncharacterized transcripts that do not code for protein. Thus, non-coding RNAs within the PFC may also play a role in neuropathic pain. Our transcriptome analysis also revealed enrichment of nonannotated transcripts derived from within and outside of gene bodies (non-annotated in $\mathrm{mm} 9$ genome assembly) (Alvarado et al., 2013). While little is known regarding their function, reports suggest that non-coding RNAs within specific cell types and neuroanatomical structures may be artifacts of chromatin remodeling (Mercer et al., 2008). Specific examples of non-coding RNAs have also been shown to mediate antisense repression in primary afferent neurons (Zhao et al., 2013) and to act as epigenetic regulators in the nucleus accumbens in neuropathy (Imai et al., 2011). Given their diverse functions and origins, more studies and deeper sequencing are required to reveal a causal role of non-coding RNAs to chronic pain (Stefani and Slack, 2008; Mercer et al., 2009).

A growing body of literature using sequencing technology has revealed transcriptome signatures in illnesses that are co-morbid with chronic pain in the PFC, including depression (Sibille et al., 2004), sleep disorders (Maret et al., 2007), anxiety (Sibille et al., 2004; Virok et al., 2011), and cognitive impairment (Wood et al., 2013; Humphries and Kohli, 2014). While geneticists have long sought a heritable mutational basis for disease susceptibility, genome-wide association studies and the search for such genes have found few risk alleles that account for these phenomena in a broader population (Kraft and Hunter, 2009). In humans, the temporal transcriptomic architecture of the PFC remains consistent despite the extensive genetic variability existing in natural human populations (Colantuoni et al., 2011). Thus, factors that regulate transcriptional changes from DNA lie "above" genetic determinants.

\section{Epigenetic Mechanisms and Function in the Prefrontal Cortex}

We propose epigenetic modulation of gene expression as a mechanism contributing to long-term plasticity in the nervous system in general and in the PFC specifically in chronic pain conditions. Epigenetics is a broad term used to describe modifications to the function of a gene that do not alter the sequence of a gene itself. In the adult brain, this definition encompasses stable changes to gene function beyond those associated with cellular differentiation following somatic cell division. Epigenetic mechanisms involve transcriptional regulation through either chromatin modification or through the covalent modification of the DNA molecule itself. The addition of a methyl group to the 5' position of the cytosine ring, catalyzed by DNA methyl transferase, DNMT1, has been reported to interact with transcripts and inhibit the methylation of particular genomic loci (Di Ruscio et al., 2013). This is particularly interesting given the abundance of non-coding RNAs within the brain of injured animals. Furthermore, the methyl moiety of methylated DNA can be further modified by hydroxylation (Kriaucionis and Heintz, 2009) and carboxylation catalyzed by TET enzymes (Ito et al., 2010). More recently, the term "epigenetics" has begun to incorporate other mechanisms of regulation that function through higher order chromatin folding (Cremer and Cremer, 2010), non-coding RNAs (Flanagan and Wild, 2007) and editing of mRNAs. Here we will focus primarily on DNA methylation as a molecular medium for storing broad, longterm changes in transcription in the PFC in chronic pain conditions.

Genomic methylation can be distributed within CpG dinucleotides (Bird, 1986) and non-CpG elements (Ramsahoye et al., 2000). In the adult mouse brain, $75 \%$ of this methylation occurs within CpG nucleotides (Guo et al., 2013) and in most tissues, methylation is stable, with only $\sim 6 \%$ variation in differential methylation between tissues (Lister et al., 2009; Hon et al., 2013; Ziller et al., 2013). Differential methylation that occurs within these $6 \%$ cytosines can regulate transcription and splicing through multiple mechanisms. By regulating which genes are and are not expressed in an individual cell, DNA methylation allows the same genomic DNA to encode the multitude of phenotypes in multicellular organisms which emerge with cellular differentiation, such as the difference between brain cells and skin cells within the same individual (Razin and Riggs, 1980). For example, increased DNA methylation in promoters or enhancers silences their activity through the recruitment of transcriptional repressors and/or steric hindrance of methyl groups (Stein et al., 1982; Comb and Goodman, 1990). In contrast, increases in DNA methylation within gene bodies are associated with actively transcribing genes (Lister et al., 2009; Hon et al., 2013). However, it is unclear whether the methylation in gene bodies plays a role in regulation of gene expression as most of the studies documenting this are descriptive and there is no clear mechanism that links gene body methylation and either transcription initiation or elongation. It is clear that the issue of "gene body methylation" requires better biochemistry which has been completely lacking in the recent flurry of genome wide mapping studies. Additionally, DNA methylation has been implicated in regulating alternative splicing in mammals (Shukla et al., 2011) and invertebrates (Foret et al., 2012) by pausing transcriptional machinery within stretches of methylated DNA. Perhaps the only strong evidence to date on the role of DNA methylation in controlling gene expression comes from the pioneering studies of Doerfler (Vardimon et al., 1982) and Razin and Cedar (Stein et al., 1982) from the early $80 \mathrm{~s}$ which showed that promoter methylation completely silences gene expression of transfected viral and genomic promoters. These studies have been repeated numerous times and, without exception, methylation of promoters silences gene expression. However, the mechanisms have been more difficult 
to understand. There is paucity of biochemical data that truly examines mechanisms of promoter silencing. The strongest data comes from pioneering studies in early nineties showing that binding of transcription factor is inhibited by methylation of the recognition element $\mathrm{g}$ (Comb and Goodman, 1990). In addition to this simple and attractive mechanism, a chromatinbased mechanism was proposed in the late nineties. Bird has suggested that methylated DNA binding proteins (MBDs; Nan et al., 1998) recruit complexes such as histone deacetylases that result in an inactive chromatin structure. However, later data (Baubec et al., 2013) shed some doubt on this simplistic understanding of the role of MBDs as they were found to bind both methylated and unmethylated genes as well as active and inactive genes. Although MeCP2 was proposed to be a ubiquitous suppressor of methylated promoters, analysis of gene expression in MeCP2 knock outs revealed silencing of 85\% of transcripts whose expression was changed and conversely overexpression of $\mathrm{MeCp} 2$ resulted in induction of most genes that were altered by MeCP2 overexpression (Chahrour et al., 2008).

\section{Role of DNA Methylation in the Brain: Learning, Memory and Neurodegenerative Disease}

In the brain, DNA methylation is a dynamic process throughout the entire life cycle. For example, in the developing mammalian brain, methylomes of neurons are widely reconfigured during synaptogenesis (Lister et al., 2013). In adults, DNA methylation is involved in memory and synaptic plasticity (Miller and Sweatt, 2007; Day and Sweatt, 2010) possibly through the regulation of DNMT3A/B in the forebrain (Feng et al., 2010). These patterns of DNA methylation have elucidated several molecular signatures underlying mental illness related to maternal deprivation (Weaver et al., 2004a; Massart et al., 2014b), depression (McGowan et al., 2009) and sleep disorders (Massart et al., 2014a).

A causal role between DNA methylation in the brain and learning and memory is supported by data from contextual fear learning paradigms showing, for example, aberrant and reversible methylation of calcineurin and brain derived neurotropic factor, both known regulators of synaptic plasticity (Lubin et al., 2008; Miller et al., 2010). In addition, the causal role of DNA methylating machinery (DNMTs) and their pharmacological inhibition have been directly linked to several additional learning paradigms (Miller and Sweatt, 2007; Miller et al., 2008; Feng et al., 2010; Day et al., 2013). The role of DNA methylation within the brain has been further extended to the transduction of epigenetic marks into the germ line and the transmission of heritable traits related to olfactory behaviors (Dias and Ressler, 2014). Finally, the role of DNA methylation in the brain has been extended to pathological mental health conditions. For instance, in a recent epigenetic-wide association study in human autopsied brains, the methylation status of several CpGs was significantly associated with the burden of Alzheimer's pathology (De Jager et al., 2014). In schizophrenia, DNA methylation profiles from the frontal cortex have shown aberrant downstream methylation of candidate regulators of disease pathology (Numata et al., 2014; Walton et al., 2014).

Hypothesis: Alterations in DNA Methylation in the Prefrontal Cortex Following Nerve Injury Mediate the Long-Term Genomic Impact of Pain as a Fundamental Mechanism Contributing to the Chronicity of Pain. This Mechanism Raises the Potential of Dna Methylation-Modulating Therapy for Reversing Chronic Pain.

Our hypothesis underlines the importance of epigenetic regulation of PFC plasticity in chronic pain (Figure 1). We have previously reported hypomethylation in the PFC and amygdala 6 months following peripheral nerve injury (Tajerian et al., 2013). The amygdala is implicated in fear and anxiety, modulates the PFC and is modulated by it. Thus, we hypothesize that chronic pain leaves lasting changes in DNA methylation that stably alter genomic programming and could be responsible for pain chronicity and painassociated co-morbidities. We have also previously shown that housing mice in environments with social and physical enrichment attenuated nerve injury-related changes in genomic hypomethylation within the PFC and reduced pain-like behaviors. We therefore also hypothesize that pain-related changes in methylation within the PFC are dynamic. While the changes in global DNA methylation demonstrate a shift in the DNA modification landscape related to pain-associated brain plasticity, the impact of altered DNA methylation on transcriptional regulation of individual genes remains to be clarified.

\section{Synaptotagmin II: A Proof-of-Principle Case Study}

Our hypothesis predicts that changes in DNA methylation in promoters and enhancers of individual genes will result in alterations in gene expression contributing to pain-related changes in brain structure and function. In order to test our hypothesis, we selected Synaptotagmin II (syt2) [GenBank: AL596207.10] as our test case. Syt2, a known regulator of synaptic function, belongs to a family of membrane-trafficking proteins, is involved in synaptic vesicle docking and fusion, and acts as a calcium sensor for fast neurotransmitter release. Since syt2 was previously shown to be upregulated in the PFC of neuropathic mice 6 months after injury (Alvarado et al., 2013), whether this dysregulation is under epigenetic control was investigated. To identify the 5' regulatory regions of the gene we utilized previously deciphered whole epigenome map of regulatory regions in the mouse genome (ENCODE Project Consortium, 2011) to identify areas of the gene with promoterlike activity. A H3K4me3 peak (a histone modification which is a hallmark of promoters) (ENCODE Project Consortium, 2011) was located downstream of the transcription start site of the gene (see map in Figure 2) and the state of methylation of this region was mapped in the PFC in nerve injured and control mice.

Pyrosequencing analysis of the methylation state of $11 \mathrm{CpG}$ sites residing downstream of the syt2 transcriptional start 


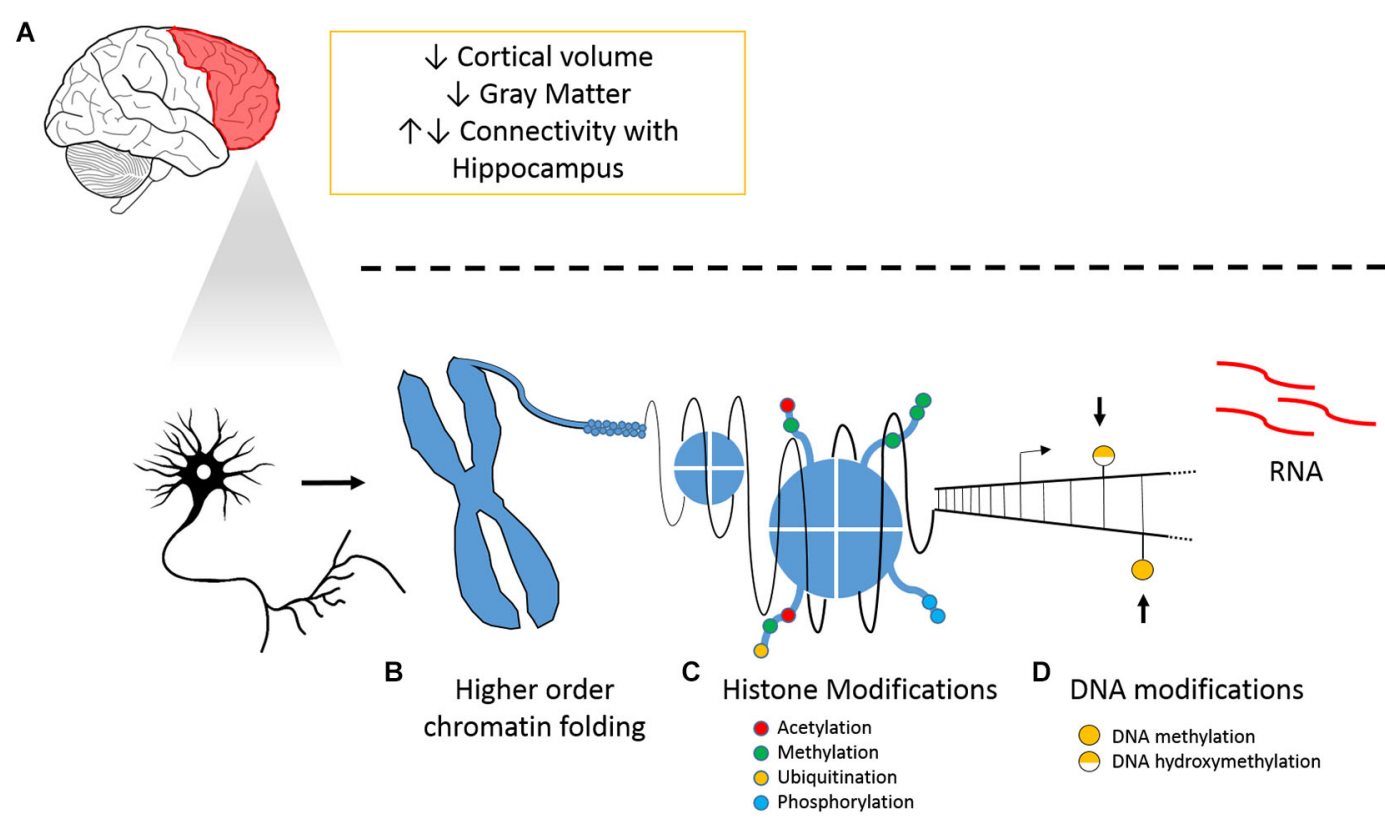

FIGURE 1 | Chronic pain and its tissue specific and cellular effects on the PFC. (A) Overview of neuroanatomical and molecular changes that accompany pain and illustrations of (B) higher order chromatin folding, (C) histone modification; and (D) DNA modifications.

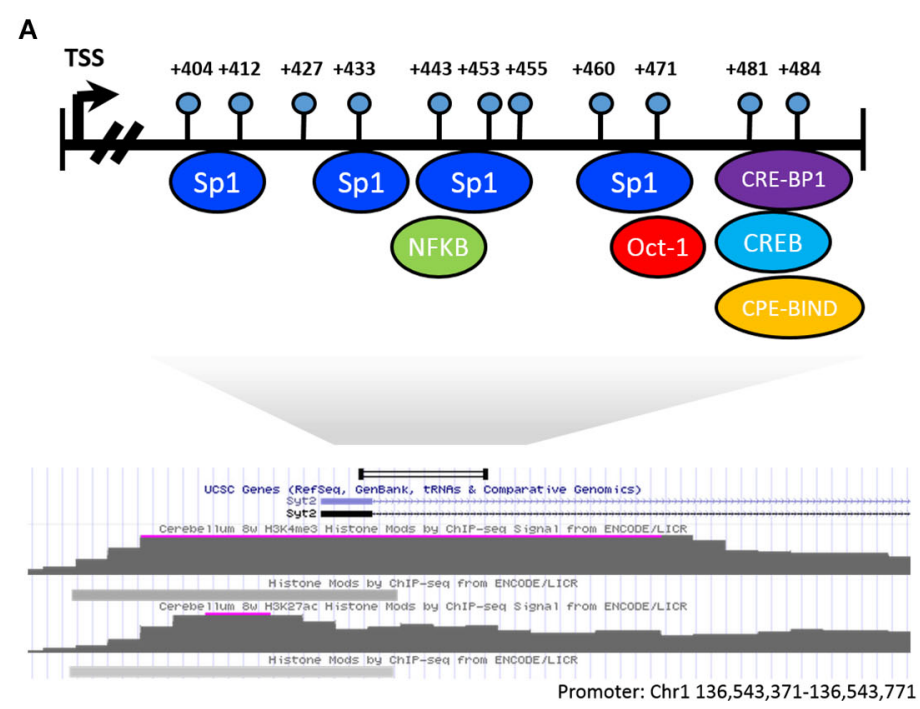

B

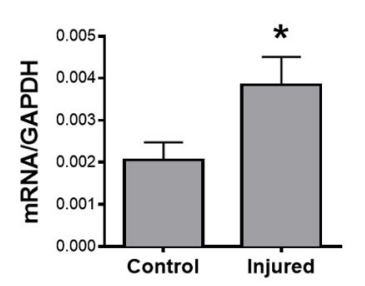

D

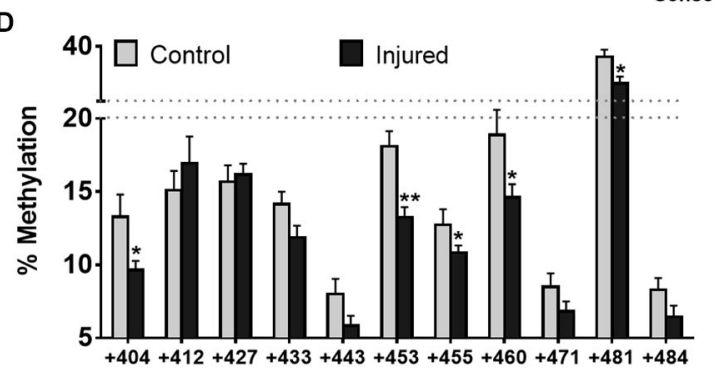

\section{C}

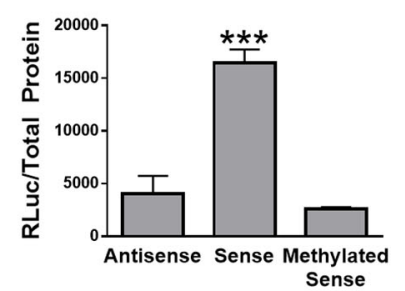

Sense

FIGURE 2 | DNA methylation and transcriptional regulation of the Syt2 Promoter. (A) Physical map of the syt2 regulatory region with predicted transcription factor binding sites below. (B) Transcription of Syt2 in control and injured animals $n=6$ /group. (C) Luciferase promoter assay of the syt2 promoter cloned into pCpGl in antisense, sense, and methylated sense directions.

site (TSS; Figure 2A) showed significant hypomethylation in the nerve injured group compared to controls (Figure 2B, $n=6$ /group). In order to directly determine whether methylation of $C G$ sites in this syt2 regulatory region affects the ability of this region to activate transcription, the region was subcloned into a CpG-deficient luciferase reporter; the same region was subcloned
Transcription in the sense direction is blocked by methylation of the syn2 promoter $n=3$ /group. (D) Bisulfite methylation mapping of the putative syt2 promoter upstream of the syt2 transcriptional start site (TSS) demonstrating neuropathy-induced decreases in DNA methylation at multiple sites ${ }^{*}=p<0.05,{ }^{* *}=p<0.005,{ }^{* * *}=p<0.001$. Error bars $=$ SEM. 
reporters were transiently transfected into HEK293 cells. The luciferase assay results demonstrated that this syt2 region directs transcriptional activity that is inhibited by the same methylation of CG sites that are differentially methylated in vivo in response to nerve injury (Figure 2C, $n=3$ /group). Interestingly, we observe changes in DNA methylation in a very limited area in the promoter. This is consistent with the hypothesis that DNA methylation silences promoter activity through interference with binding of factors discussed above. For example, we have shown previously that epigenetic programming by maternal care of the Glucocorticoid receptor gene involves site specific changes in one CG which is also the binding site for the transcription factor NGFI-A (Weaver et al., 2004a). We showed that methylation of the NGFI-A binding site inhibits NGFI-A binding and silences promoter activity (Weaver et al., 2007). Further, experiments are required to identify the transcription factor that is inhibited by DNA methylation in the syt2 promoter.

Examination of syt2 methylation in animals that were subjected to nerve injury provides evidence in support of the hypothesis that DNA methylation regulates gene expression within the PFC in chronic pain. These changes were observed in the brain long after the original peripheral injury. Thus, our data provides a proof of principle for DNA methylation of regulatory regions as a mechanism for long-term reprogramming of gene expression in response to peripheral nerve injury. Further experiments are required to determine the full importance of this mechanism in reprogramming gene expression in the central nervous system following a chronic pain-producing injury.

Syt2 expression is critical for synaptic transmission in caudal and forebrain regions (Pang et al., 2006; Kochubey and Schneggenburger, 2011). In general, synaptotagmin is a marker of synaptic density and plasticity and its increase is correlated with synaptogenesis (Masliah and Terry, 1993). Our data are consistent with previous findings showing increased syt2 expression in the PFC of rats subjected to chronic restraint stress (Virok et al., 2011), supporting the hypothesis that chronic anxiety/stress (regardless if its source being chronic restraint or chronic pain) could result in profound changes in synaptic structure and/or function.

\section{Epigenetics of Chronic Pain: Current Understanding and Future Directions}

While the role of DNA methylation in regulating transcription has been extensively validated, we are only beginning to understand its full effects on a genomic landscape. For example, DNA methylation within the PFC following nerve injury decreased by $12 \%$, accounting for $\sim 180,000 \mathrm{CpG}$ sites across the genome (Tajerian et al., 2013). A 12\% decrease in methylation relating directly to transcripts within the genome would reflect a dramatic effect on the transcriptome. However, we only observed a change of 800 protein coding transcripts considering $>1.5 \%$ of our genome codes for protein (Lander et al., 2001). Furthermore this observation does not account for cytosine methylation that occurs outside of a CpG dinucleotide that has been considered to be more widely distributed within the brain
(Lister et al., 2013). This supports additional roles for DNA methylation and their relation to chromosomal integrity (Eden et al., 2003) and higher order chromatin structure (JimenezUseche et al., 2013). For example, telomeric and centromeric repeats are $\mathrm{CpG}$-dense and heavily methylated in post-mitotic cells (Yoder et al., 1997; Han et al., 2008). Increased methylation at these sites would involve condensation of chromatin and increased stability of higher order structures. We speculate that such hypomethylation would also implicate repetitive elements within the genome such as SINE/LINE transposable elements, also shown to affect nuclear structure by defining chromosomal breaking points as seen in immunodeficiency disorders (Tuck-Muller et al., 2000). Our promoter analysis (Table 1) and differential transcriptome, shows a depletion of weak promoters ( $\mathrm{CpG}$ island rich). This suggests that the protein-coding component of our data may rely on the DNA methylation of $\mathrm{CpG}$ island poor promoters (narrow- and broadtype promoters). As a result this extends our interpretation of genomic hypermethylation outside of the scope of protein coding genes. Our interpretation of genomic hypomethylation is limited by our approach using a restriction enzyme-coupled assay and not a comprehensive view of which genomic areas become hypomethylated in pain. Future studies using approaches such as methylated DNA immunoprecipitation and sequencing will offer the necessary resolution needed to reveal the nature of DNA methylation associated with pain.

The data collected thus far is limited to a single time point 6 months post-injury. It will be important to gain a temporal understanding of pain-related changes in DNA methylation. Future studies should examine that time course of changes within the brain. Are there wide-spread changes in methylation throughout the CNS one day after an injury? One month? Three months? Exactly what genes are dysregulated at each of these time points? Do these changes precede the development of cognitive or emotional changes or vice versa?

Given the magnitude of the pain-related changes in global methylation, it was surprising that no changes were observed in any of the known regulators of methylation (i.e., DNMTs, methylated DNA binding proteins) in our transcriptomic screen of the PFC. Is this because massive dysregulation of hypermethylation/hypomethylation through the DMNTs occurs early after injury but by 6 months has reached a new steady state? Given the chronicity of pain and its co-morbidities, we believe that the processes underlying neuroplasticity are part of the etiology of the disease and exist in a continuum of cause and effect. For example, while co-morbidities of chronic pain may not manifest themselves early following injury, the emergence of co-morbidities may initiate a cascade of transcriptional changes in the brain that program long-term changes. This cascade, modulated by DNA methylation and other epigenetic processes over the course of months to years, may feed into the pathology of chronic pain, thus increasing the burden of the disease. Would that imply that pain-related changes in methylation are more difficult to reverse months vs. days after injury? All of these questions merit further exploration. However, it should be noted that DNA methylation states of genes are regulated by many factors in addition to global levels of enzyme such as local 
presence of transcription factors and chromatin states of genomic loci, these rather than global changes in enzyme levels might be the determining causal agents of changes in DNA methylation in chronic pain.

Interpretation of changes of DNA methylation in the brain, as compared to other tissues, is complicated by cell heterogeneity. In the brain, it is difficult to attribute altered patterns of methylation to specific cell types. In Lister et al., mapping of the brain methylome, cell sorting enabled distinction between neurons compared to astrocytes (Lister et al., 2013). However, there is still extensive heterogeneity of neuronal cell types even within a single brain region. This is particularly important given that neurons within the PFC have more inter-individual variability in DNA methylation than do other cell types within the same tissue (Iwamoto et al., 2011). The difficulties in interpreting these changes are obvious when one considers a hypothetical brain region where there is $0 \%$ methylation at all glia-specific alleles and $100 \%$ methylation at all neuronal specific alleles, resulting in an observation that $\sim 50 \%$ methylation. Future studies examining the contributions of different neuronal and non-neuronal cells using either cell sorting or histological methods are needed to begin to unravel these complexities.

It is important to note that epigenetic changes are not independent of one another. A great deal of crosstalk between DNA methylation has been reported (D'Alessio et al., 2007; Ou et al., 2007; Brinkman et al., 2012). It is therefore important to examine additional layers of epigenetic regulation. This additional tier of regulation may hold clues into the mechanisms of chronicity, specifically regarding the expression of specific gene families.

Finally, while this manuscript uses the example of syn 2 to illustrate the main hypothesis, the role of individual genes or gene families is virtually unexplored. While some differentially methylated sites may be critically important in pain-related neuroplasticity, it is likely that many are not. Understanding epigenetic regulation at both the genome-wide and the genespecific levels will provide insights into how chronic pain changes the brain and how to reverse it.

\section{Epigenetics of Chronic Pain: Potential Therapeutic Targets}

One fundamental difference between epigenetic regulation and genetic polymorphisms is the potential of the former to be modulated by pharmacological manipulations (Szyf, 1994, 2009). In rodents, the behavioral impact of early life experience (i.e., maternal care) is reversible in the adult offspring with epigenetic drugs (Weaver et al., 2004a,b, 2005, 2006). The potential therapeutic value of interventions targeting epigenetic mechanisms underlying chronic pain has exciting clinical significance.

To date, most pharmacological interventions directly targeting epigenetic mechanisms have been used to provide evidence of epigenetic involvement rather than to explore viable treatment options. However, with the increased emphasis on pain epigenetics, it is plausible that more targeted approaches could be applied to the treatment of pain and its related comorbidities at the peripheral, spinal, and supraspinal levels. Currently, small molecule drugs targeting epigenetic machinery function globally, modifying the genome across multiple cells and tissues. Appropriate targeting of epigenetic therapeutics is needed to enhance specificity and reduce systemic side-effects. This targeting can be tissue-, cell- or gene-specific. Although this statement reflects common wisdom that good agents should be "magic bullets" it isn't clear that "dirty" drugs will not have a therapeutic value. It is possible that general DNA methylation inhibitors such as RG108 (Machnes et al., 2013) or methyl donors such as SAM (Fuso et al., 2011) or general HDAC inhibitors such as SAHA (Hahnen et al., 2006) would be effective in treating chronic pain with the appropriate dosing and scheduling. Moreover, since DNA methylation associated with chronic pain appear to be widespread, it is possible that general modulators of DNA methylation that act system-wide will be required.

Although gene-targeting DNA methylation modifiers are still only a hypothetical approach, of potential therapeutic value might be gene-specific epigenetic targeting through recently developed genome editing technology. For example, TET-TALE fusion proteins have been shown to effectively target and demethylate individual genes in vitro (Maeder et al., 2013) and the recent development of Cas9 systems offer novel and flexible approaches to individual gene targeting ( $\mathrm{Hsu}$ et al., 2014). While these approaches offer $\sim 20-100$ bp resolution, their development remains in its infancy and they have only been developed as tools for research.

The therapeutic interventions currently thought to offer some benefits through DNA methylation exist include nutritional inputs such as folate and other methyl donor intermediates. Relevant to neuropathy, folate has been shown to aide axonal regeneration in a dose-dependent manner through DNA methylation machinery and folate metabolism (Iskandar et al., 2010). Similarly, other methyl donors such as dietary choline are critical for fetal hippocampal brain development via genomic and gene-specific DNA methylation patterns (Niculescu et al., 2006).

\section{Concluding Remarks}

Despite its high prevalence, little is known about the brain mechanisms underlying chronic pain and its associated comorbidities. This hypothesis paper builds upon previous publications where we propose that DNA methylation contributes to the chronic changes in behavior and gene expression in neuropathic mice. Furthermore, it provides proof of principle evidence for linking peripheral injury-triggered central changes in DNA methylation and transcriptional regulation. Finally, we propose that long-term alterations in DNA methylation could provide a molecular substrate for chronic pain-related changes in the CNS, forming a "memory trace" for pain in the brain.

\section{Acknowledgments}

This work was funded by CIHR MOP-102586 to LSS, CIHR MOP-42411 to MS, a Pfizer Canada Neuropathic Pain Research 
Award to LSS and MS and a gift from the Sackler McGill Program in Psychobiology and Epigenetics to MS. MT was

\section{References}

Alvarado, S., Tajerian, M., Millecamps, M., Suderman, M., Stone, L. S., and Szyf, M. (2013). Peripheral nerve injury is accompanied by chronic transcriptomewide changes in the mouse prefrontal cortex. Mol. Pain 9:21. doi: 10.1186/17448069-9-21

Apkarian, A. V., Baliki, M. N., and Geha, P. Y. (2009). Towards a theory of chronic pain. Prog. Neurobiol. 87, 81-97. doi: 10.1016/j.pneurobio.2008.09.018

Apkarian, A. V., Bushnell, M. C., Treede, R. D., and Zubieta, J. K. (2005). Human brain mechanisms of pain perception and regulation in health and disease. Eur. J. Pain 9, 463-484. doi: 10.1016/j.ejpain.2004.11.001

Apkarian, A. V., Sosa, Y., Krauss, B. R., Thomas, P. S., Fredrickson, B. E., Levy, R. E., et al. (2004). Chronic pain patients are impaired on an emotional decision-making task. Pain 108, 129-136. doi: 10.1016/j.pain.2003. 12.015

Baubec, T., Ivanek, R., Lienert, F., and Schubeler, D. (2013). Methylationdependent and -independent genomic targeting principles of the MBD protein family. Cell 153, 480-492. doi: 10.1016/j.cell.2013.03.011

Berger, S. E., Baria, A. T., Baliki, M. N., Mansour, A., Herrmann, K. M., Torbey, S., et al. (2014). Risky monetary behavior in chronic back pain is associated with altered modular connectivity of the nucleus accumbens. BMC Res. Notes 7:739. doi: 10.1186/1756-0500-7-739

Bird, A. P. (1986). CpG-rich islands and the function of DNA methylation. Nature 321, 209-213. doi: 10.1038/321209a0

Brinkman, A. B., Gu, H., Bartels, S. J., Zhang, Y., Matarese, F., Simmer, F., et al. (2012). Sequential ChIP-bisulfite sequencing enables direct genome-scale investigation of chromatin and DNA methylation cross-talk. Genome Res. 22, 1128-1138. doi: 10.1101/gr.133728.111

Cardoso-Cruz, H., Lima, D., and Galhardo, V. (2013a). Impaired spatial memory performance in a rat model of neuropathic pain is associated with reduced hippocampus-prefrontal cortex connectivity. J. Neurosci. 33, 2465-2480. doi: 10.1523/JNEUROSCI.5197-12.2013

Cardoso-Cruz, H., Sousa, M., Vieira, J. B., Lima, D., and Galhardo, V. (2013b). Prefrontal cortex and mediodorsal thalamus reduced connectivity is associated with spatial working memory impairment in rats with inflammatory pain. Pain 154, 2397-2406. doi: 10.1016/j.pain.2013.07.020

Centeno, M. V., Mutso, A., Millecamps, M., and Apkarian, A. V. (2009). Prefrontal cortex and spinal cord mediated anti-neuropathy and analgesia induced by sarcosine, a glycine-T1 transporter inhibitor. Pain 145, 176-183. doi: 10.1016/j. pain.2009.06.014

Chahrour, M., Jung, S. Y., Shaw, C., Zhou, X., Wong, S. T., Qin, J., et al. (2008). $\mathrm{MeCP} 2$, a key contributor to neurological disease, activates and represses transcription. Science 320, 1224-1229. doi: 10.1126/science.1153252

Colantuoni, C., Lipska, B. K., Ye, T., Hyde, T. M., Tao, R., Leek, J. T., et al. (2011). Temporal dynamics and genetic control of transcription in the human prefrontal cortex. Nature 478, 519-523. doi: 10.1038/nature10524

Comb, M., and Goodman, H. M. (1990). CpG methylation inhibits proenkephalin gene expression and binding of the transcription factor AP-2. Nucleic Acids Res. 18, 3975-3982. doi: 10.1093/nar/18.13.3975

Cremer, T., and Cremer, M. (2010). Chromosome territories. Cold Spring Harb. Perspect. Biol. 2:a003889. doi: 10.1101/cshperspect.a003889

D'Alessio, A. C., Weaver, I. C., and Szyf, M. (2007). Acetylation-induced transcription is required for active DNA demethylation in methylation-silenced genes. Mol. Cell. Biol. 27, 7462-7474. doi: 10.1128/mcb.01120-07

Davis, K. D., Pope, G., Chen, J., Kwan, C. L., Crawley, A. P., and Diamant, N. E. (2008). Cortical thinning in IBS: implications for homeostatic, attention and pain processing. Neurology 70, 153-154. doi: 10.1212/01.wnl.0000295509. 30630.10

Day, J. J., Childs, D., Guzman-Karlsson, M. C., Kibe, M., Moulden, J., Song, E., et al. (2013). DNA methylation regulates associative reward learning. Nat. Neurosci. 16, 1445-1452. doi: 10.1038/nn.3504

Day, J. J., and Sweatt, J. D. (2010). DNA methylation and memory formation. Nat. Neurosci. 13, 1319-1323. doi: 10.1038/nn.2666 supported by a studentship from The Louise and Alan Edwards Foundation.

De Jager, P. L., Srivastava, G., Lunnon, K., Burgess, J., Schalkwyk, L. C., Yu, L. et al. (2014). Alzheimer's disease: early alterations in brain DNA methylation at ANK1, BIN1, RHBDF2 and other loci. Nat. Neurosci. 17, 1156-1163. doi: 10. $1038 / \mathrm{nn} .3786$

Dias, B. G., and Ressler, K. J. (2014). Parental olfactory experience influences behavior and neural structure in subsequent generations. Nat. Neurosci. 17, 89-96. doi: 10.1038/nn.3594

Di Ruscio, A., Ebralidze, A. K., Benoukraf, T., Amabile, G., Goff, L. A., Terragni, J., et al. (2013). DNMT1-interacting RNAs block gene specific DNA methylation. Nature 503, 371-376. doi: 10.1038/nature12598

Eden, A., Gaudet, F., Waghmare, A., and Jaenisch, R. (2003). Chromosomal instability and tumors promoted by DNA hypomethylation. Science 300:455. doi: $10.1126 /$ science. 1083557

ENCODE Project Consortium (2011). A user's guide to the encyclopedia of DNA elements (ENCODE). PLoS Biol. 9:e1001046. doi: 10.1371/journal.pbio. 1001046

Feng, J., Zhou, Y., Campbell, S. L., Le, T., Li, E., Sweatt, J. D., et al. (2010). Dnmt1 and Dnmt3a maintain DNA methylation and regulate synaptic function in adult forebrain neurons. Nat. Neurosci. 13, 423-430. doi: 10.1038/nn.2514

Flanagan, J. M., and Wild, L. (2007). An epigenetic role for noncoding RNAs and intragenic DNA methylation. Genome Biol. 8:307. doi: 10.1186/gb-20078-6-307

Foret, S., Kucharski, R., Pellegrini, M., Feng, S., Jacobsen, S. E., Robinson, G. E., et al. (2012). DNA methylation dynamics, metabolic fluxes, gene splicing and alternative phenotypes in honey bees. Proc. Natl. Acad. Sci. U S A 109, 4968-4973. doi: 10.1073/pnas. 1202392109

Freeman, S. H., Kandel, R., Cruz, L., Rozkalne, A., Newell, K., Frosch, M. P., et al. (2008). Preservation of neuronal number despite age-related cortical brain atrophy in elderly subjects without Alzheimer disease. J. Neuropathol. Exp. Neurol. 67, 1205-1212. doi: 10.1097/NEN.0b013e31818fc72f

Fuso, A., Nicolia, V., Cavallaro, R. A., and Scarpa, S. (2011). DNA methylase and demethylase activities are modulated by one-carbon metabolism in Alzheimer's disease models. J. Nutr. Biochem. 22, 242-251. doi: 10.1016/j.jnutbio.2010. 01.010

Giesecke, T., Gracely, R. H., Grant, M. A., Nachemson, A., Petzke, F., Williams, D. A., et al. (2004). Evidence of augmented central pain processing in idiopathic chronic low back pain. Arthritis Rheum. 50, 613-623. doi: 10.1002/art.20063

Guo, J. U., Su, Y., Shin, J. H., Shin, J., Li, H., Xie, B., et al. (2013). Distribution, recognition and regulation of non-CpG methylation in the adult mammalian brain. Nat. Neurosci. 17, 215-222. doi: 10.1038/nn.3607

Hahnen, E., Eyüpoglu, I. Y., Brichta, L., Haastert, K., Tränkle, C., Siebzehnrübl, F. A., et al. (2006). In vitro and ex vivo evaluation of second-generation histone deacetylase inhibitors for the treatment of spinal muscular atrophy. $J$. Neurochem. 98, 193-202. doi: 10.1111/j.1471-4159.2006.03868.x

Han, L., Su, B., Li, W.-H., and Zhao, Z. (2008). CpG island density and its correlations with genomic features in mammalian genomes. Genome Biol. 9:R79. doi: 10.1186/gb-2008-9-5-r79

Hon, G. C., Rajagopal, N., Shen, Y., McCleary, D. F., Yue, F., Dang, M. D., et al. (2013). Epigenetic memory at embryonic enhancers identified in DNA methylation maps from adult mouse tissues. Nat. Genet. 45, 1198-1206. doi: 10. 1038/ng.2746

Hötting, K., and Röder, B. (2013). Beneficial effects of physical exercise on neuroplasticity and cognition. Neurosci. Biobehav. Rev. 37, 2243-2257. doi: 10. 1016/j.neubiorev.2013.04.005

Hsu, P. D., Lander, E. S., and Zhang, F. (2014). Development and applications of CRISPR-Cas9 for genome engineering. Cell 157, 1262-1278. doi: 10.1016/j.cell. 2014.05.010

Humphries, C., and Kohli, M. A. (2014). Rare variants and transcriptomics in Alzheimer disease. Curr. Genet. Med. Rep. 2, 75-84. doi: 10.1007/s40142 014-0035-9

Imai, S., Saeki, M., Yanase, M., Horiuchi, H., Abe, M., Narita, M., et al. (2011). Change in microRNAs associated with neuronal adaptive responses in the nucleus accumbens under neuropathic pain. J. Neurosci. 31, 15294-15299. doi: 10.1523/JNEUROSCI.0921-11.2011 
Iskandar, B. J., Rizk, E., Meier, B., Hariharan, N., Bottiglieri, T., Finnell, R. H., et al. (2010). Folate regulation of axonal regeneration in the rodent central nervous system through DNA methylation. J. Clin. Invest. 120, 1603-1616. doi: 10. 1172/JCI40000

Ito, S., D’Alessio, A. C., Taranova, O. V., Hong, K., Sowers, L. C., and Zhang, Y. (2010). Role of Tet proteins in $5 \mathrm{mC}$ to $5 \mathrm{hmC}$ conversion, ES-cell selfrenewal and inner cell mass specification. Nature 466, 1129-1133. doi: 10. 1038/nature09303

Iwamoto, K., Bundo, M., Ueda, J., Oldham, M. C., Ukai, W., Hashimoto, E., et al. (2011). Neurons show distinctive DNA methylation profile and higher interindividual variations compared with non-neurons. Genome Res. 21, 688-696. doi: 10.1101/gr.112755.110

Jimenez-Useche, I., Ke, J., Tian, Y., Shim, D., Howell, S. C., Qiu, X., et al. (2013). DNA methylation regulated nucleosome dynamics. Sci. Rep. 3:2121. doi: 10. 1038/srep02121

Khan, S. A., Keaser, M. L., Meiller, T. F., and Seminowicz, D. A. (2014). Altered structure and function in the hippocampus and medial prefrontal cortex in patients with burning mouth syndrome. Pain 155, 1472-1480. doi: 10.1016/j. pain.2014.04.022

Kochubey, O., and Schneggenburger, R. (2011). Synaptotagmin increases the dynamic range of synapses by driving $\mathrm{Ca}^{2+}$-evoked release and by clamping a near-linear remaining $\mathrm{Ca}^{2+}$ sensor. Neuron 69, 736-748. doi: 10.1016/j.neuron. 2011.01.013

Kraft, P., and Hunter, D. J. (2009). Genetic risk prediction--are we there yet? N. Engl. J. Med. 360, 1701-1703. doi: 10.1056/NEJMp0810107

Krause, T., Asseyer, S., Taskin, B., Flöel, A., Witte, A. V., Mueller, K., et al. (2014). The cortical signature of central poststroke pain: gray matter decreases in somatosensory, insular and prefrontal cortices. Cereb. Cortex doi: 10. 1093/cercor/bhu177. [Epub ahead of print].

Kriaucionis, S., and Heintz, N. (2009). The nuclear DNA base 5hydroxymethylcytosine is present in Purkinje neurons and the brain. Science 324, 929-930. doi: 10.1126/science.1169786

Kuchinad, A., Schweinhardt, P., Seminowicz, D. A., Wood, P. B., Chizh, B. A., and Bushnell, M. C. (2007). Accelerated brain gray matter loss in fibromyalgia patients: premature aging of the brain? J. Neurosci. 27, 4004-4007. doi: 10. 1523/jneurosci.0098-07.2007

Lander, E. S., Linton, L. M., Birren, B., Nusbaum, C., Zody, M. C., Baldwin, J., et al. (2001). Initial sequencing and analysis of the human genome. Nature 409, 860-921. doi: 10.1038/35057062

Lenhard, B., Sandelin, A., and Carninci, P. (2012). Metazoan promoters: emerging characteristics and insights into transcriptional regulation. Nat. Rev. Genet. 13, 233-245. doi: 10.1038/nrg3163

Lister, R., Mukamel, E. A., Nery, J. R., Urich, M., Puddifoot, C. A., Johnson, N. D., et al. (2013). Global epigenomic reconfiguration during mammalian brain development. Science 341:1237905. doi: 10.1126/science.1237905

Lister, R., Pelizzola, M., Dowen, R. H., Hawkins, R. D., Hon, G., TontiFilippini, J., et al. (2009). Human DNA methylomes at base resolution show widespread epigenomic differences. Nature 462, 315-322. doi: 10.1038/nature 08514

Low, L. A. (2013). The impact of pain upon cognition: what have rodent studies told us? Pain 154, 2603-2605. doi: 10.1016/j.pain.2013.06.012

Lubin, F. D., Roth, T. L., and Sweatt, J. D. (2008). Epigenetic regulation of BDNF gene transcription in the consolidation of fear memory. J. Neurosci. 28, 10576-10586. doi: 10.1523/JNEUROSCI.1786-08.2008

Machnes, Z. M., Huang, T. C., Chang, P. K., Gill, R., Reist, N., Dezsi, G., et al. (2013). DNA methylation mediates persistent epileptiform activity in vitro and in vivo. PLoS One 8:e76299. doi: 10.1371/journal.pone.0076299

Maeder, M. L., Angstman, J. F., Richardson, M. E., Linder, S. J., Cascio, V. M., Tsai, S. Q., et al. (2013). Targeted DNA Demethylation and endogenous gene activation using programmable TALE-TET1 fusions. Nat. Biotechnol. 31, 1137-1142. doi: 10.1038/nbt.2726

Maret, S., Dorsaz, S., Gurcel, L., Pradervand, S., Petit, B., Pfister, C., et al. (2007). Homerla is a core brain molecular correlate of sleep loss. Proc. Natl. Acad. Sci. U S A 104, 20090-20095. doi: 10.1073/pnas.0710131104

Masliah, E., and Terry, R. (1993). The role of synaptic proteins in the pathogenesis of disorders of the central nervous system. Brain Pathol. 3, 77-85. doi: 10 . 1111/j.1750-3639.1993.tb00728.x

Massart, R., Freyburger, M., Suderman, M., Paquet, J., El Helou, J., BelangerNelson, E., et al. (2014a). The genome-wide landscape of DNA methylation and hydroxymethylation in response to sleep deprivation impacts on synaptic plasticity genes. Transl. Psychiatry 4:e347. doi: 10.1038/tp.2013.120

Massart, R., Suderman, M., Provencal, N., Yi, C., Bennett, A. J., Suomi, S., et al. (2014b). Hydroxymethylation and DNA methylation profiles in the prefrontal cortex of the non-human primate rhesus macaque and the impact of maternal deprivation on hydroxymethylation. Neuroscience 268, 139-148. doi: 10.1016/j. neuroscience.2014.03.021

McGowan, P. O., Sasaki, A., D’Alessio, A. C., Dymov, S., Labonté, B., Szyf, M., et al. (2009). Epigenetic regulation of the glucocorticoid receptor in human brain associates with childhood abuse. Nat. Neurosci. 12, 342-348. doi: 10.1038/ nn. 2270

Mercer, T. R., Dinger, M. E., and Mattick, J. S. (2009). Long non-coding RNAs: insights into functions. Nat. Rev. Genet. 10, 155-159. doi: 10.1038/nrg2521

Mercer, T. R., Dinger, M. E., Sunkin, S. M., Mehler, M. F., and Mattick, J. S. (2008). Specific expression of long noncoding RNAs in the mouse brain. Proc. Natl. Acad. Sci. U S A 105, 716-721. doi: 10.1073/pnas.0706729105

Metz, A. E., Yau, H. J., Centeno, M. V., Apkarian, A. V., and Martina, M. (2009). Morphological and functional reorganization of rat medial prefrontal cortex in neuropathic pain. Proc. Natl. Acad. Sci. U S A 106, 2423-2428. doi: 10. 1073/pnas.0809897106

Miller, C. A., Campbell, S. L., and Sweatt, J. D. (2008). DNA methylation and histone acetylation work in concert to regulate memory formation and synaptic plasticity. Neurobiol. Learn. Mem. 89, 599-603. doi: 10.1016/j.nlm.2007. 07.016

Miller, C. A., Gavin, C. F., White, J. A., Parrish, R. R., Honasoge, A., Yancey, C. R., et al. (2010). Cortical DNA methylation maintains remote memory. Nat. Neurosci. 13, 664-666. doi: 10.1038/nn.2560

Miller, C. A., and Sweatt, J. D. (2007). Covalent modification of DNA regulates memory formation. Neuron 53, 857-869. doi: 10.1016/j.neuron.2007.02.022

Mutso, A. A., Radzicki, D., Baliki, M. N., Huang, L., Banisadr, G., Centeno, M. V., et al. (2012). Abnormalities in hippocampal functioning with persistent pain. J. Neurosci. 32, 5747-5756. doi: 10.1523/JNEUROSCI.0587-12.2012

Nan, X., Ng, H. H., Johnson, C. A., Laherty, C. D., Turner, B. M., Eisenman, R. N., et al. (1998). Transcriptional repression by the methyl-CpG-binding protein MeCP2 involves a histone deacetylase complex. Nature 393, 386-389. doi: 10. $1038 / 30764$

Neugebauer, V., Galhardo, V., Maione, S., and Mackey, S. C. (2009). Forebrain pain mechanisms. Brain Res. Rev. 60, 226-242. doi: 10.1016/j.brainresrev.2008

Nicholson, B., and Verma, S. (2004). Comorbidities in chronic neuropathic pain. Pain Med. 5(Suppl. 1), S9-S27. doi: 10.1111/j.1526-4637.2004.04019.x

Niculescu, M. D., Craciunescu, C. N., and Zeisel, S. H. (2006). Dietary choline deficiency alters global and gene-specific DNA methylation in the developing hippocampus of mouse fetal brains. FASEB J. 20, 43-49. doi: 10.1096/fj.05$4707 \mathrm{com}$

Numata, S., Ye, T., Herman, M., and Lipska, B. K. (2014). DNA methylation changes in the postmortem dorsolateral prefrontal cortex of patients with schizophrenia. Front. Genet. 5:280. doi: 10.3389/fgene.2014.00280

Ou, J. N., Torrisani, J., Unterberger, A., Provençal, N., Shikimi, K., Karimi, M., et al. (2007). Histone deacetylase inhibitor Trichostatin A induces global and gene-specific DNA demethylation in human cancer cell lines. Biochem. Pharmacol. 73, 1297-1307. doi: 10.1016/j.bcp.2006.12.032

Pang, Z. P., Melicoff, E., Padgett, D., Liu, Y., Teich, A. F., Dickey, B. F., et al. (2006). Synaptotagmin-2 is essential for survival and contributes to $\mathrm{Ca}^{2+}$ triggering of neurotransmitter release in central and neuromuscular synapses. J. Neurosci. 26, 13493-13504. doi: 10.1523/jneurosci.3519-06.2006

Pleger, B., Draganski, B., Schwenkreis, P., Lenz, M., Nicolas, V., Maier, C., et al. (2014). Complex regional pain syndrome type I affects brain structure in prefrontal and motor cortex. PLoS One 9:e85372. doi: 10.1371/journal.pone. 0085372

Poh, K. W., Yeo, J. F., Stohler, C. S., and Ong, W. Y. (2012). Comprehensive gene expression profiling in the prefrontal cortex links immune activation and neutrophil infiltration to antinociception. J. Neurosci. 32, 35-45. doi: 10. 1523/JNEUROSCI.2389-11.2012

Ramsahoye, B. H., Biniszkiewicz, D., Lyko, F., Clark, V., Bird, A. P., and Jaenisch, R. (2000). Non-CpG methylation is prevalent in embryonic stem cells and may be mediated by DNA methyltransferase 3a. Proc. Natl. Acad. Sci. U S A 97, 5237-5242. doi: 10.1073/pnas.97.10.5237

Razin, A., and Riggs, A. D. (1980). DNA methylation and gene function. Science 210, 604-610. doi: 10.1126/science.6254144 
Ruscheweyh, R., Willemer, C., Krüger, K., Duning, T., Warnecke, T., Sommer, J., et al. (2011). Physical activity and memory functions: an interventional study. Neurobiol. Aging 32, 1304-1319. doi: 10.1016/j.neurobiolaging.2009. 08.001

Schmidt-Wilcke, T., Leinisch, E., Gänssbauer, S., Draganski, B., Bogdahn, U., Altmeppen, J., et al. (2006). Affective components and intensity of pain correlate with structural differences in gray matter in chronic back pain patients. Pain 125, 89-97. doi: 10.1016/j.pain.2006.05.004

Schmidt-Wilcke, T., Leinisch, E., Straube, A., Kämpfe, N., Draganski, B., Diener, H. C., et al. (2005). Gray matter decrease in patients with chronic tension type headache. Neurology 65, 1483-1486. doi: 10.1212/01.wnl.0000183067. 94400.80

Schmidt-Wilcke, T., Luerding, R., Weigand, T., Jürgens, T., Schuierer, G., Leinisch, E., et al. (2007). Striatal grey matter increase in patients suffering from fibromyalgia--a voxel-based morphometry study. Pain 132(Suppl. 1), S109-S116. doi: 10.1016/j.pain.2007.05.010

Schwartz, N., Temkin, P., Jurado, S., Lim, B. K., Heifets, B. D., Polepalli, J. S., et al. (2014). Chronic pain. Decreased motivation during chronic pain requires long-term depression in the nucleus accumbens. Science 345, 535-542. doi: 10. $1126 /$ science. 1253994

Seminowicz, D. A., Laferriere, A. L., Millecamps, M., Yu, J. S., Coderre, T. J., and Bushnell, M. C. (2009). MRI structural brain changes associated with sensory and emotional function in a rat model of long-term neuropathic pain. Neuroimage 47, 1007-1014. doi: 10.1016/j.neuroimage.2009.05.068

Seminowicz, D. A., Wideman, T. H., Naso, L., Hatami-Khoroushahi, Z., Fallatah, S., Ware, M. A., et al. (2011). Effective treatment of chronic low back pain in humans reverses abnormal brain anatomy and function. J. Neurosci. 31, 7540-7550. doi: 10.1523/JNEUROSCI.5280-10.2011

Sharp, J., and Keefe, B. (2005). Psychiatry in chronic pain: a review and update. Curr. Psychiatry Rep. 7, 213-219. doi: 10.1007/s11920-005-0056-x

Shukla, S., Kavak, E., Gregory, M., Imashimizu, M., Shutinoski, B., Kashlev, M., et al. (2011). CTCF-promoted RNA polymerase II pausing links DNA methylation to splicing. Nature 479, 74-79. doi: 10.1038/nature10442

Sibille, E., Arango, V., Galfalvy, H. C., Pavlidis, P., Erraji-Benchekroun, L., Ellis, S. P., et al. (2004). Gene expression profiling of depression and suicide in human prefrontal cortex. Neuropsychopharmacology 29, 351-361. doi: 10. 1038/sj.npp. 1300335

Stefani, G., and Slack, F. J. (2008). Small non-coding RNAs in animal development. Nat. Rev. Mol. Cell Biol. 9, 219-230. doi: 10.1038/nrm2347

Stein, R., Razin, A., and Cedar, H. (1982). In vitro methylation of the hamster adenine phosphoribosyltransferase gene inhibits its expression in mouse $\mathrm{L}$ cells. Proc. Natl. Acad. Sci. U S A 79, 3418-3422. doi: 10.1073/pnas.79. 11.3418

Szyf, M. (1994). DNA methylation properties: consequences for pharmacology. Trends Pharmacol. Sci. 15, 233-238. doi: 10.1016/0165-6147(94)90317-4

Szyf, M. (2009). Epigenetics, DNA methylation and chromatin modifying drugs. Annu. Rev. Pharmacol. Toxicol. 49, 243-263. doi: 10.1146/annurev-pharmtox061008-103102

Tagliazucchi, E., Balenzuela, P., Fraiman, D., and Chialvo, D. R. (2010). Brain resting state is disrupted in chronic back pain patients. Neurosci. Lett. 485, 26-31. doi: 10.1016/j.neulet.2010.08.053

Tajerian, M., Alvarado, S., Millecamps, M., Vachon, P., Crosby, C., Bushnell, M. C., et al. (2013). Peripheral nerve injury is associated with chronic, reversible changes in global DNA methylation in the mouse prefrontal cortex. PLoS One 8:e55259. doi: 10.1371/journal.pone.0055259

Tajerian, M., and Clark, J. D. (2015). The role of the extracellular matrix in chronic pain following injury. Pain 156, 366-370. doi: 10.1097/01.j.pain.0000460323. $80020.9 \mathrm{~d}$

Tajerian, M., Leu, D., Zou, Y., Sahbaie, P., Li, W., Khan, H., et al. (2014). Brain neuroplastic changes accompany anxiety and memory deficits in a model of complex regional pain syndrome. Anesthesiology 121, 852-865. doi: 10 . 1097/ALN.0000000000000403
Tuck-Muller, C. M., Narayan, A., Tsien, F., Smeets, D. F., Sawyer, J., Fiala, E. S., et al. (2000). DNA hypomethylation and unusual chromosome instability in cell lines from ICF syndrome patients. Cytogenet. Cell Genet. 89, 121-128. doi: 10. $1159 / 000015590$

Vardimon, L., Kressmann, A., Cedar, H., Maechler, M., and Doerfler, W. (1982). Expression of a cloned adenovirus gene is inhibited by in vitro methylation. Proc. Natl. Acad. Sci. U S A 79, 1073-1077. doi: 10.1073/pnas.79.4.1073

Virok, D. P., Kis, Z., Szegedi, V., Juhász, G., Zvara, A. Jr., Müller, G., et al. (2011). Functional changes in transcriptomes of the prefrontal cortex and hippocampus in a mouse model of anxiety. Pharmacol. Rep. 63, 348-361. doi: 10.1016/s1734-1140(11)70501-1

Walton, E., Liu, J., Hass, J., White, T., Scholz, M., Roessner, V., et al. (2014). MB-COMT promoter DNA methylation is associated with working-memory processing in schizophrenia patients and healthy controls. Epigenetics 9, 1101-1107. doi: 10.4161/epi.29223

Weaver, I. C., Cervoni, N., Champagne, F. A., D’Alessio, A. C., Sharma, S., Seckl, J. R., et al. (2004a). Epigenetic programming by maternal behavior. Nat. Neurosci. 7, 847-854. doi: 10.1038/nn1276

Weaver, I. C., Champagne, F. A., Brown, S. E., Dymov, S., Sharma, S., Meaney, M. J., et al. (2005). Reversal of maternal programming of stress responses in adult offspring through methyl supplementation: altering epigenetic marking later in life. J. Neurosci. 25, 11045-11054. doi: 10.1523/jneurosci.365205.2005

Weaver, I. C., D’Alessio, A. C., Brown, S. E., Hellstrom, I. C., Dymov, S., Sharma, S., et al. (2007). The transcription factor nerve growth factor-inducible protein a mediates epigenetic programming: altering epigenetic marks by immediateearly genes. J. Neurosci. 27, 1756-1768. doi: 10.1523/jneurosci.416406.2007

Weaver, I. C., Diorio, J., Seckl, J. R., Szyf, M., and Meaney, M. J. (2004b). Early environmental regulation of hippocampal glucocorticoid receptor gene expression: characterization of intracellular mediators and potential genomic target sites. Ann. N Y Acad. Sci. 1024, 182-212. doi: 10.1196/annals.1321.099

Weaver, I. C., Meaney, M. J., and Szyf, M. (2006). Maternal care effects on the hippocampal transcriptome and anxiety-mediated behaviors in the offspring that are reversible in adulthood. Proc. Natl. Acad. Sci. U S A 103, 3480-3485. doi: 10.1073/pnas.0507526103

Wood, S. H., Craig, T., Li, Y., Merry, B., and de Magalhaes, J. P. (2013). Whole transcriptome sequencing of the aging rat brain reveals dynamic RNA changes in the dark matter of the genome. Age (Dordr.) 35, 763-776. doi: 10. 1007/s11357-012-9410-1

Yoder, J. A., Walsh, C. P., and Bestor, T. H. (1997). Cytosine methylation and the ecology of intragenomic parasites. Trends Genet. 13, 335-340. doi: 10. 1016/s0168-9525(97)01181-5

Zhao, X., Tang, Z., Zhang, H., Atianjoh, F. E., Zhao, J. Y., Liang, L., et al. (2013). A long noncoding RNA contributes to neuropathic pain by silencing Kcna2 in primary afferent neurons. Nat. Neurosci. 16, 1024-1031. doi: 10.1038/ nn.3438

Ziller, M. J., Gu, H., Müller, F., Donaghey, J., Tsai, L. T.-Y., Kohlbacher, O., et al. (2013). Charting a dynamic DNA methylation landscape of the human genome. Nature 500, 477-481. doi: 10.1038/nature12433

Conflict of Interest Statement: The authors declare that the research was conducted in the absence of any commercial or financial relationships that could be construed as a potential conflict of interest.

Copyright () 2015 Alvarado, Tajerian, Suderman, Machnes, Pierfelice, Millecamps, Stone and Szyf. This is an open-access article distributed under the terms of the Creative Commons Attribution License (CC BY). The use, distribution and reproduction in other forums is permitted, provided the original author(s) or licensor are credited and that the original publication in this journal is cited, in accordance with accepted academic practice. No use, distribution or reproduction is permitted which does not comply with these terms. 